American Journal of Pharmaceutical Education 2018; 82 (1) Article 6167.

\title{
RESEARCH
}

\section{Team-Based Learning Experiences of Fourth-Year Pharmacy Students in a South African University}

\author{
Mariet J. Eksteen, MPharm, ${ }^{\text {a,b }}$ Gerda M. Reitsma, PhD, ${ }^{b}$ Sonet B. Swart, $\mathrm{PhD},{ }^{a}$ Erika Fourie, $\mathrm{PhD}^{\mathrm{b}}$ \\ ${ }^{a}$ University of the Free State, Bloemfontein, South Africa \\ ${ }^{\mathrm{b}}$ North-West University, Potchefstroom, South Africa \\ Submitted November 9, 2016; accepted January 10, 2017; published February 2018.
}

Objective. To determine fourth-year pharmacy students' learning experiences with team-based learning (TBL) at a South African university.

Methods. A survey composed of biographical data and quantitative questions focusing on student learning experiences was sent to students. There were $183(91.5 \%)$ students who completed the survey. Results. Students had a positive experience with TBL and found it valuable and more worthwhile than traditional lecture methods, regardless of their initial negative perception of TBL. Students enjoyed working in multi-cultural, mixed gender teams.

Conclusion. TBL is an effective teaching strategy to simulate the reality of health professions where practitioners are required to work in a team. TBL should be offered in more courses in health professions curriculum in South Africa to strengthen and promote efficient health care delivery.

Keywords: team-based learning, pharmacy students, pharmacy education, learning experiences, health professions education

\section{INTRODUCTION}

The purpose of team-based learning (TBL) is to deepen students' learning and to promote the development of high-performance learning teams. ${ }^{1}$ Larry Michaelsen developed TBL in the 1970s when he, too, was facing the same problems many lecturers today are experiencing with traditional lecture methods: low class attendance, low student engagement in class, low value of lectures because they are perceived as boring, and smallgroup work resulting in an opportunity for top achieving students to dominate group activities. ${ }^{2,3}$ Traditional lecture methods are teacher-centered and discipline-based resulting to students becoming passive learners who mostly memorize course content. ${ }^{4}$

TBL, as described in detail in publications by Michaelsen and others, aims to ensure that students engage more deeply with course content rather than simply memorizing facts before an assessment or examination. ${ }^{1-3,5-8}$ TBL fosters students to become accountable for their own preparation and contribution to their team. With TBL, students must collectively decide and come to a conclusion

Corresponding Author: Mariet J. Eksteen, Department of Pharmacy Practice, School of Pharmacy, Internal Box 286, Private Bag X6001, Hoffman St. 11, North-West University, Potchefstroom, 2520, South Africa. Tel: +27(0)18-299-1021. Fax: +27(0)18-299-4244. E-mail: Mariet.Eksteen@nwu.ac.za of what is best based on real-life case studies and theoretical principles.

For the optimal learning experience during TBL, each team must have sufficient and approximately the same level of resources to draw from during the application exercises. To ensure this, teams must be as diverse as possible (ie, each team should consist of a mix of student characteristics in relation to the course content, eg, previous course work completed and demographic characteristics like gender and ethnicity). ${ }^{1}$ Because the TBL class does not include a formal, elaborate, theoretical lecture like in traditional lectures, all theories applicable to a specific scheduled class should be studied and accomplished before the class. It is crucial that students understand basic theoretical concepts and ideas for them to be able to contribute and successfully complete the application exercise. In the application exercise, teams discuss and debate real-life case studies to decide on a correct answer. During peer evaluation, the team evaluates each member's individual preparation for team work, class attendance, positive contribution to team discussions, and value of their input. ${ }^{1}$

Although several publications in the Journal focused on TBL and its outcome in terms of course grades, ${ }^{9}$ perception of faculty members, ${ }^{10}$ comparison with traditional lecture-based learning, ${ }^{11}$ or student performance and perception, ${ }^{12}$ no article specifically focused on the learning experiences of students where TBL was the sole 


\section{American Journal of Pharmaceutical Education 2018; 82 (1) Article 6167.}

method of instruction. This is also the first report on TBL implementation in a South African university's school of pharmacy. This study formed part of a larger research project on the development of guidelines for TBL in an undergraduate pharmacy curriculum in South Africa. In this article, we aim to determine fourth-year pharmacy students' learning experiences of TBL as used in a pharmacy practice course of the Bachelor of Pharmacy curriculum after their exposure to TBL.

\section{METHODS}

A survey was developed using data from a literature review on TBL in undergraduate health professions education and data gathered in the previous phases of the larger research project. The survey included biographical questions such as gender, age and ethnic group as well as 19 quantitative questions focusing on students' learning experiences. The 19 Likert-type questions were answered using a 4 -scale rating $(1=$ strongly disagree, $2=$ disagree, $3=$ agree, $4=$ strongly agree). Berk recommends measuring teaching effectiveness with an even-numbered scale to avoid a midpoint option that serves as an escape anchor. ${ }^{13}$ Respondents may only choose one answer per question and had to answer all the questions.

The survey was tested through an exploratory investigation to detect errors in content and/or clarity before being used in the main investigation. ${ }^{14}$ Cognitive interviews were conducted with students who were similar but not part of the study population to see whether the potential respondent understood the questions in general, understood all the words in the questions, could provide the relevant answer(s), and could provide any advice on whether the question should be restructured, rephrased or stay as is, as recommended by Wills. ${ }^{15}$ Experts in the field of health professions education and pharmacy were asked to review the survey for content validity and to give their opinion on aspects such as the clarity and distinctness of the questions, the amount of time needed to complete the questions, any bias that may be created by the questions, and any other suggestions and/or recommendations. The completed surveys from students and experts were captured in the same way as the data from participants to ensure that the data from the surveys can easily be transferred into electronic data sheets for statistical analysis. All comments and suggestions were included in the survey to improve the quality after which the survey was sent to a statistician for final evaluation on face validity. The Flesch-Kincaid readability tool was used to assess the complexity of the text. A grade 8 complexity level was recommended as the maximum targeted level. ${ }^{16}$ The level of this survey was 7 .
Fourth-year pharmacy students enrolled in a management course in the 2016 academic year formed the target population $(\mathrm{N}=200)$, as TBL was introduced in this course for the first time in this year. Since the target population was easily accessible with little difference in time and cost to collect the data from the entire target population, all students were invited to complete the survey. However, not all students agreed to participate and/or gave consent that their data may be used, which resulted in a sample population of $183(91.5 \%)$ students. Pearson's chi-square test was used to determine if the sample represented the target in terms of age, gender and ethnicity. $P$ values greater than $.05(.67, .91$ and .79 , respectively) indicated no statistically significant association. Thus, the sample population represented the target population in terms of biographical data (Table 1). All completed survey received were included in the study.

The survey was completed during class when the target population was present. Pharmacy students were informed upfront of the date when the data would be collected. There was only one opportunity to participate in this research study. Due to data being collected anonymously, it was not possible to validate if a student who asked to complete a survey at a later date did not already complete it.

An information leaflet was distributed to all potential participants prior to this class to provide them time to decide whether they'd like to participate in this study. They were not obligated to participate. The leaflet contained information about the study, its purpose, researchers, procedures, benefits, risks/discomforts, cost/ remuneration, access to data, inquiries, funding, ethical approval and feedback on the findings. Students who agreed to participate gave written informed consent and handed it in with the survey but in separate containers to

Table 1. Biographical Data of Target and Sample Population Gender, Age, and Ethnic Group

\begin{tabular}{|c|c|c|c|c|}
\hline & \multicolumn{2}{|c|}{ Target Population } & \multicolumn{2}{|c|}{ Sample Population } \\
\hline & $\mathbf{n}$ & $\%$ & $\mathbf{n}$ & $\%$ \\
\hline \multicolumn{5}{|l|}{ Gender } \\
\hline Male & 41 & 20.5 & 34 & 18.8 \\
\hline Female & 159 & 79.5 & 147 & 81.2 \\
\hline \multicolumn{5}{|l|}{ Age in years ${ }^{a}$} \\
\hline 22 and younger & 130 & 65.0 & 117 & 64.3 \\
\hline 23 & 45 & 22.5 & 44 & 24.2 \\
\hline 24 and older & 25 & 12.5 & 21 & 11.5 \\
\hline \multicolumn{5}{|l|}{ Ethnic group } \\
\hline White & 183 & 91.5 & 166 & 91.2 \\
\hline Other & 17 & 8.5 & 16 & 8.8 \\
\hline
\end{tabular}




\section{American Journal of Pharmaceutical Education 2018; 82 (1) Article 6167.}

adhere to anonymity. Participation in this research was entirely voluntary and participants were free to decline participation or to withdraw from the study at any point, even if they did agree to take part initially. However, if they handed in their anonymous completed survey, there was no way of tracing the survey back to the student and the data could not be withdrawn at that stage.

The research was conducted according to the ethical guidelines and principles of the International Declaration of Helsinki and the National Health Research Ethics Council (NHREC) of South Africa. Ethical approval for this study was granted by the applicable faculty's ethics committee prior to commencement of the research.

The data were captured manually using Microsoft Excel (Redmond, WA) with options 1 to 4 for each question. After all data were captured, a random $10 \%$ of data entries were spot checked for accuracy, and data error identification and rectification measures were applied as an iterative process. Since there was no way to trace a survey back to the student, missing data could not be followed up and were left as is.

The IBM SPSS Statistics version 23, release 23.0.0 (Armonk, NY) was used to analyze the data. ${ }^{17}$ Descriptive statistics was used to summarize the collected data. Since this is a newly developed survey, exploratory factor analysis (EFA) was conducted to explore the structure of constructs within the data. The Kaiser-Meyer-Olkin (KMO) measure of sampling adequacy indicated whether there was sufficient data available for this specific analysis. The KMO calculated in this study of 0.76 was higher than the guideline value of $0.7,{ }^{18}$ indicating that the data source provided a sufficient number of data points to continue with the analysis. Bartlett's test of sphericity determines if there is enough correlation between the different items (questions) in the survey for the analysis to be considered appropriate. The guideline value for this test is $p<.05 .^{18}$ The reported $p$ value $(p<.001)$ for this study indicated that there was enough correlation between the items. It is also important to confirm that there was not too much correlation between items. In order to confirm that this is not the case in a study, the determinant should be greater than $0.00001 .{ }^{18}$ In this study, the calculated determinant was 0.03 , which is higher than the guideline value, and confirmed that the correlations between different questions in the survey are not so high that they all implied the same question. The five extracted factors resulting from the Oblimin rotation and Principal Axis factoring methods explain a total variance of $57.7 \%$. The aim of a factor analysis is data reduction, thus to group questions measuring the same underlying construct into factors while simultaneously explaining as much as possible the variation within the data. The number of extracted factors should explain at least $50 \%$ of the data to be considered acceptable. The factor loadings in the pattern matrix indicated the following grouping of questions together: questions 1 and 2 (previous experience), questions 3 and 4 (external motivation to prepare for class), questions 5 to 8 (class attendance and participation), questions 9 to 12 (working in teams), and questions 13 to 19 (experience of TBL). The EFA indicated that question 8 was loaded onto the "class attendance and participation" factor. However, based on the literature study, it made more theoretical sense to group this question with questions 9 to 12 , the "working in a team" factor.

Although the EFA indicated that questions 1 and 2 form a factor, Cronbach's alpha indicated inadequate reliability $(\alpha=0.14)$ since it was below the guideline value of 0.7. ${ }^{19}$ Therefore it was decided to analyze them separately going forward as "negative perception of TBL" for question 1 and "usual preparation in advance for all classes" for question 2 . The other four factors' reliability was confirmed with Cronbach's alpha above $0.7:{ }^{19}$ external motivation to prepare for class (questions 3 and 4; $\alpha=0.66 ; 3.2(0.7))$, class attendance and participation (questions 5 to $8 ; \alpha=0.74 ; 3.4(0.6)$ ), working in teams (questions 8 to $12 ; \alpha=0.66 ; 3.4(0.4)$ ), and experience of TBL (questions 13 to $19 ; \alpha=0.78 ; 3.0(0.52)$ ).

To evaluate to what extent the extracted factors fits the data, a confirmatory factor analysis (CFA) by means of a structural equation model (SEM) was conducted using Amos 23.0.0 (build 817) (IBM Corporation, Armonk, NY). It was confirmed that all the items contributed significantly to the factors, as indicated by the $p<.05$. These goodness-of-fit statistics, which consist of different measures, determine how well the covariance structure predicted by the model's factors correspond to the covariance structure in the data. ${ }^{20}$ These fit measures can be grouped into five broad categories namely: absolute fit measures, relative fit measures, parsimony-based fit measures, fit indices based on the non-central Chisquare-distribution and information-theoretic fit measures. $^{21}$ It is advisable to report indices from at least three of the broad categories. Model fit was assessed using four different indices from four different categories. Chi-square test statistics (2.28) were close to the guideline value of 1 which indicated a good fit. The comparative fit index $(\mathrm{CFI}=0.83)$ still reflected a reasonable fit although it was slightly less than the guideline value of 0.95 . A root mean square error approximation (RMSEA) of maximum 0.10 indicates a good fit. The RMSEA for this study was $0.08(0.07 ; 0.09)$, indicating that the model fits the data well. 


\section{American Journal of Pharmaceutical Education 2018; 82 (1) Article 6167.}

\section{RESULTS}

The majority of the study participants were female $(n=147), 22$ years of age $(64.3 \%)$ and white $(91.2 \%)$ (Table 1).

Table 2 contains the results of the descriptive statistics of the TBL survey's data. The majority of students (69.4\%) initially had a negative perception of TBL directly after being introduced to it (Q1). More than half of the students $(53.3 \%)$ admitted that they do not usually prepare in advance for class (Q2). However, TBL changed this situation as only $15.3 \%$ of the students indicated that TBL did not motivate them to prepare for class $\left(\mathrm{Q} 3^{\mathrm{a}}\right)$, even though it would be expected of them to discuss their opinions during class (Q4). TBL also increased most of the students' class attendance (88\%, Q5), class participation (95\%, Q7), and reduced the likelihood of them feeling sleepy during class $(88 \%$, Q6). Students experienced working in teams positively, with $78.1 \%$ of them indicating that they preferred working in multicultural teams (Q8) and 95.1\% preferring mixed gender teams (Q9). Most students (98.4\%) felt that they contributed to their team's activities (Q12 ${ }^{\mathrm{b}}$ ) and nearly all of them $(96.8 \%)$ were positive about working with their peers (Q10). From previous experiences, students generally viewed group evaluations, especially peer evaluations, negatively. However, in TBL, 75\% of the students indicated that they enjoyed the use of peer evaluation activities $\left(\mathrm{Q}^{\mathrm{b}}{ }^{\mathrm{b}}\right)$ and working in a team $(95.1 \%$, Q11). Overall, more than $80 \%$ of the students enjoyed the learning $\left(\mathrm{Q} 14^{\mathrm{a}}\right)$ and team experience $\left(\mathrm{Q} 13^{\mathrm{b}}\right)$, and $68 \%$ of the students agreed that TBL should be offered more often in the BPharm curriculum $(\mathrm{Q} 15)$ as the time spent on TBL is more worthwhile $\left(\mathrm{Q} 16^{\mathrm{a}}\right)$ and valuable $(\mathrm{Q} 17)$ than traditional lectures. Over $90 \%$ of the students also reported that TBL was an effective teaching strategy to simulate the reality of the health professions team (Q19) and as motivation to give their best (Q18 $)$.

It should be noted that $p$-values are reported for completeness sake, but will not be interpreted, since a convenience sample instead of a random sample was used. Interpretation will be based on the effect sizes.

Spearman's rho is a correlation coefficient that indicates the relationship between two variables, eg, age and a specific factor. The guideline values indicate that 0.1 is a small effect or practically non-significant relationship, 0.3 is a medium effect or practically visible relationship, and 0.5 is a large effect or practically significant relationship. ${ }^{22}$ The $p$ values indicate whether there is a statistically significant correlation, the guideline value being less than .05 .

The correlation between age and experience of TBL $(r=0.19, p=.01)$ leans toward a practically visible relationship, which is also statistically significant. Practically and statistically non-significant correlations were reported between age and all other factors $(r<=0.10$ and $p>=.18)$.

Spearman's rho indicated practically visible to practically significant relationships or medium to large correlations between the following constructs: external motivation to prepare for class with experience of TBL $(r=0.37)$, class attendance and participation with experience of TBL $(r=0.42)$, and working in teams with experience of TBL $(r=0.39)$. The correlation between class attendance and participation with working in teams tended toward practical significance $(r=0.46)$. All these correlations were statistically significant due to $p$ values smaller than .05 .

Independent $t$-tests were used to compare the mean scores of continuous dependent variables, eg, factor scores, to test for differences between groups of categorical or independent variables: gender (male/female) or ethnicity (white/other). ${ }^{23}$ These tests indicate whether there is a statistically significant difference in the mean scores of the two groups. If the $p$ value is less than .05 , there is a statistically significant difference. ${ }^{23}$ The effect size indicates the practical significance of the differences between the means of the two groups. The guideline values as described by Cohen indicates that an effect size of 0.2 is small and has no practical significance, an effect size of 0.5 is medium and indicates practically visible differences, and an effect size of 0.8 is large and indicates practically significant differences. ${ }^{24}$ In Table 3, the independent $t$-tests results for gender groups resulted in statistically significant and practically visible differences for initial negative perception of TBL $(d=0.44, p=.03)$, external motivation to prepare for class $(d=0.51, p=.01)$, and working in a team $(d=0.44, p=.02)$. In all cases except on usual preparation in advance for all classes, female students agreed more than male students.

For ethnicity, the independent $t$-tests did not indicate any statistically significant results, but practically visible differences for an initial negative perception of TBL was found $(d=0.44, p=.07)$. Usual preparation in advance for all classes $(d=0.31, p=19)$ and working in a team $(d=0.30, p=20)$ indicated small to medium practically significant differences between ethnic groups. Students who indicated white as their ethnic orientation were less negative regarding TBL in the beginning Mean (SD) 2.8 (0.9) and enjoyed working in teams more $3.4(0.4)$ but usually prepare less for class in general $2.4(0.8)$ than students from other ethnic groups.

\section{DISCUSSION}

The purpose of this study was to determine fourthyear pharmacy students' learning experience with the use of TBL in a pharmacy practice course. It was the first time 
American Journal of Pharmaceutical Education 2018; 82 (1) Article 6167.

Table 2. Results of the Team-Based Learning (TBL) Survey on Learning Experiences

\begin{tabular}{|c|c|c|c|c|c|}
\hline & \multicolumn{4}{|c|}{ Percentage (\%) } & \multirow[b]{2}{*}{ M (SD) } \\
\hline & $\begin{array}{l}\text { Strongly } \\
\text { Disagree }\end{array}$ & Disagree & \multicolumn{2}{|c|}{ Agree $\begin{array}{c}\text { Strongly } \\
\text { Agree }\end{array}$} & \\
\hline \multicolumn{6}{|l|}{ Negative perception of TBL } \\
\hline $\begin{array}{l}\text { Q1 I had a negative perception of team-based learning after the } \\
\text { lecturer introduced it but before we practiced it for the first time. }\end{array}$ & 9.8 & 20.8 & 47.0 & 22.4 & $2.8(0.9)$ \\
\hline \multicolumn{6}{|l|}{ Usual preparation in advance for all classes } \\
\hline Q2 I usually prepare in advance for class in most of my courses. & 15.8 & 37.7 & 37.2 & 9.3 & $2.4(0.9)$ \\
\hline \multicolumn{6}{|l|}{ External motivation to prepare for class } \\
\hline $\begin{array}{l}\text { Q3 Team-based learning did not motivate me to prepare for this } \\
\text { class. }{ }^{\text {a }}\end{array}$ & 43.2 & 41.5 & 10.4 & 4.9 & $1.8(0.8)$ \\
\hline $\begin{array}{l}\text { Q4 Knowing I would discuss my opinions during class motivated } \\
\text { me to review study material prior to class. }\end{array}$ & 1.1 & 10.4 & 50.8 & 37.7 & $3.3(0.7)$ \\
\hline \multicolumn{6}{|l|}{ Class attendance and participation } \\
\hline $\begin{array}{l}\text { Q5 Team-based learning increased my class attendance compared to } \\
\text { traditional lectures. }\end{array}$ & 6.0 & 6.0 & 24.6 & 63.4 & $3.5(0.9)$ \\
\hline $\begin{array}{l}\text { Q6 I am more likely to feel sleepy during traditional lectures than } \\
\text { during classes using team-based learning activities. }\end{array}$ & 2.7 & 9.3 & 36.1 & 51.9 & $3.4(0.8)$ \\
\hline Q7 Team-based learning increased my participation in the classroom. & 1.6 & 3.3 & 39.3 & 55.7 & $3.5(0.7)$ \\
\hline \multicolumn{6}{|l|}{ Working in teams } \\
\hline Q8 I prefer to work in a multi-cultural team. & 4.4 & 17.5 & 45.9 & 32.2 & $3.1(0.8)$ \\
\hline Q9 I prefer a mixed gender team. & 0.5 & 4.4 & 45.4 & 49.7 & $3.4(0.6)$ \\
\hline Q10 I am positive about working with my peers in the classroom. & 0.5 & 2.7 & 44.3 & 52.5 & $3.5(0.6)$ \\
\hline Q11 I work well as a participant in a team. & 0.5 & 4.4 & 47.5 & 47.5 & $3.4(0.6)$ \\
\hline Q12 I contributed fully to my team's work in this course. ${ }^{\mathrm{b}}$ & 0.0 & 1.6 & 33.9 & 63.9 & $3.6(0.5)$ \\
\hline \multicolumn{6}{|l|}{ Experience of TBL } \\
\hline $\begin{array}{l}\text { Q13 I enjoyed the use of peer evaluation as part of my team } \\
\text { experience. }{ }^{\text {b }}\end{array}$ & 4.9 & 19.7 & 49.2 & 25.7 & $3.0(0.8)$ \\
\hline $\begin{array}{l}\text { Q14 The team-based learning approach made my learning experience less } \\
\text { enjoyable. }^{\text {a }}\end{array}$ & 32.8 & 54.1 & 10.4 & 2.7 & $1.8(0.7)$ \\
\hline $\begin{array}{l}\text { Q15 Team-based learning should be offered in more courses in the BPharm } \\
\text { curriculum. }\end{array}$ & 13.1 & 19.1 & 46.4 & 21.3 & $2.8(0.9)$ \\
\hline $\begin{array}{l}\text { Q16 The time spent in traditional lectures was more worthwhile } \\
\text { than time spent in team-based learning. }{ }^{\text {. }}\end{array}$ & 14.2 & 47.5 & 31.7 & 6.6 & $2.3(0.8)$ \\
\hline $\begin{array}{l}\text { Q17 Team-based learning sessions were more valuable than traditional } \\
\text { lectures. }\end{array}$ & 4.4 & 26.8 & 42.6 & 26.2 & $2.9(0.8)$ \\
\hline $\begin{array}{l}\text { Q18 Team-based learning did not motivate me to give my best in this } \\
\text { course. }^{\text {a }}\end{array}$ & 35.0 & 50.8 & 11.5 & 2.7 & $1.8(0.7)$ \\
\hline $\begin{array}{l}\text { Q19 Team-based learning is an effective teaching strategy to simulate the } \\
\text { reality of the health profession where one is required to work in a team. }\end{array}$ & 1.1 & 7.1 & 51.4 & 40.4 & $3.3(0.7)$ \\
\hline
\end{tabular}

${ }^{a}$ Questions 3, 14, 16, and 18 were stated negatively

${ }^{\mathrm{b}}$ Questions 12 and 13 were only answered by 182 participants

that TBL was implemented in a South African pharmacy school, and so there are no other data to compare this study to.

According to the South African Pharmacy Council's (SAPC) statistics, ${ }^{25}$ the majority of pharmacy students and pharmacists in South Africa are female (81.2\%), as reflected in the study population in Table 1 . This could be explained by current legislation like the Employment Equity Act $^{26}$ which aims to purposefully diversify the workplace through affirmative action to redress the 


\section{American Journal of Pharmaceutical Education 2018; 82 (1) Article 6167.}

Table 3. Independent $t$-tests between Survey Questions or Factors and Gender and Ethnicity

\begin{tabular}{|c|c|c|c|}
\hline & M (SD) & $\begin{array}{c}\text { Gender } \\
\text { Effect } \\
\text { size } t \text {-test } \\
\text { between } \\
\text { male and female } \\
(d \text {-value })^{\mathrm{a}}\end{array}$ & $\begin{array}{c}\text { Ethnicity } \\
\text { Effect } \\
\text { size } t \text {-test } \\
\text { between } \\
\text { white and other } \\
(d \text {-value })^{\text {a }}\end{array}$ \\
\hline \multicolumn{4}{|c|}{ Negative Perception of Team-Based Learning (TBL) } \\
\hline Male & $2.5(0.9)$ & 0.44 & \\
\hline Female & $2.9(0.9)$ & & \\
\hline White & $2.8(0.9)$ & & 0.44 \\
\hline Other & $3.2(0.8)$ & & \\
\hline \multicolumn{4}{|c|}{ Usual Preparation in Advance for All Classes } \\
\hline Male & $2.4(0.7)$ & 0.02 & \\
\hline Female & $2.4(0.9)$ & & \\
\hline White & $2.4(0.9)$ & & 0.31 \\
\hline Other & $2.7(0.8)$ & & \\
\hline \multicolumn{4}{|c|}{ External Motivation to Prepare for Class } \\
\hline Male & $3.0(0.7)$ & 0.51 & \\
\hline Female & $3.3(0.6)$ & & \\
\hline White & $3.2(0.7)$ & & 0.09 \\
\hline Other & $3.3(0.6)$ & & \\
\hline \multicolumn{4}{|c|}{ Class Attendance and Participation } \\
\hline Male & $3.3(0.7)$ & 0.25 & \\
\hline Female & $3.5(0.6)$ & & \\
\hline White & $3.4(0.6)$ & & 0.19 \\
\hline Other & $3.6(0.4)$ & & \\
\hline \multicolumn{4}{|c|}{ Working in a Team } \\
\hline Male & $3.3(0.4)$ & 0.44 & \\
\hline Female & $3.4(0.4)$ & & \\
\hline White & $3.4(0.4)$ & & 0.30 \\
\hline Other & $3.3(0.4)$ & & \\
\hline \multicolumn{4}{|c|}{ Experience with TBL } \\
\hline Male & $3.0(0.6)$ & 0.06 & \\
\hline Female & $3.0(0.5)$ & & \\
\hline White & $3.0(0.5)$ & & 0.21 \\
\hline Other & $3.1(0.6)$ & & \\
\hline
\end{tabular}

${ }^{\mathrm{a} A n}$ effect size of 0.2 is small, 0.5 medium and 0.8 large. ${ }^{24}$

employment inequity of apartheid and to ensure equitable representation in all occupational categories and levels in the workforce. Affirmative action is "intended to ensure that suitably qualified employees from designated groups have equal employment opportunity."26 Females are included in the description of designated groups, along with black people and people with disabilities. It is thus seen as fair discrimination in South Africa to promote affirmative action, ie, accepting a suitable female application over an equal or even higher qualified male application.

The same legislation ${ }^{26}$ is applicable for ethnicity, as black people are also part of designated groups, as described in this Act. Black people is a generic name used in this legislation for Africans, Coloureds (mixed black and white ancestry) and Indians in South Africa. These requirements as set out by legislation are also represented in the SAPC statistics ${ }^{25}$ where the majority of pharmacy students in South Africa are Africans (54\%), Coloureds $(5 \%)$ or Asians (16\%). However, when compared with Table 1, a different representation is found at the university where this study was conducted, where $91.5 \%$ of students enrolled in the course were white compared to the national average of only $24 \%$. This could be due to the primary language of instruction at this university being Afrikaans with simultaneous interpretation services in English, whereas all other eight pharmacy curriculums presented at other South African universities are only presented in English.

South African students generally enter university at the age of 18 after completing their secondary education and are expected to complete a four-year course at the age of 22. These final year students, except one, were 22 years or older. However, it is common to find students failing a course or two earlier in the curriculum which then results in an extended study period of five or more years. To a lesser extent, it does happen that students transfer from another field of study to pharmacy after one or two years or do not continue with tertiary education directly following secondary education, explaining the spread of age groups.

The study participants were in their fourth and final year and have never been exposed to a formal educational team-based strategy during their curriculum. It was thus anticipated by the researchers that students would show a negative perception of TBL when they were introduced to it on the first day of this course, mainly because of previous negative experiences of group work. This type of reaction is commonly found with students when they are uncertain of the impact of change from a passive lecture method to an active teaching strategy ${ }^{27}$ or when they fail to recognize the benefits of TBL. ${ }^{28}$ The timing of TBL implementation in the curriculum may impact students' perception of the strategy. ${ }^{11}$ Since these students were exposed to traditional teaching methods since primary and secondary school, they have a higher level of comfort with these methods and need time to adjust to TBL as a teaching strategy. ${ }^{29}$ This theory was proven as students responded positively about TBL after experiencing it for 10 weeks that indeed TBL made their learning experience more enjoyable and valuable. Time spent in TBL lectures was also more worthwhile than that spent in traditional lectures, as students were more engaged in the learning process. The students agreed that more courses in the BPharm curriculum should use TBL as teaching strategy. Unfortunately, this was the last semester consisting of formal scheduled classes for these students, so students' 


\section{American Journal of Pharmaceutical Education 2018; 82 (1) Article 6167.}

experiences of traditional lecture methods following this TBL course could not be explored. However, in previous studies, students described traditional lecture methods as frustrating due to the lack of self-directed, active learning involved. $^{30}$

More than half of the students (53.5\%) acknowledged that they do not usually prepare in advance for classes. However, the majority agreed that TBL motivated them to prepare for this class $(84.7 \%)$. Knowing that it would be expected of them to discuss their opinions during class motivated students to review the assigned reading prior to the TBL class. This finding echoes the important TBL principle that students are held accountable to both the lecturer and their team members for the quality and quantity of their individual work. ${ }^{7}$ Almost all students answered that they worked well as a participant in a team $(95 \%)$ and felt that they fully contributed to their team's work during the TBL course. To evaluate students' true contribution in terms of time and effort toward the team, peer evaluation was used to assess their contribution to team activities. The majority of students enjoyed the use of peer evaluation as part of their team experience (74.9\%), which indicates that their teammates' preparation and contributions were acceptable otherwise it would not have been as enjoyable.

Students are aware of the passive nature of traditional lecture methods and its effects: low class attendance, ${ }^{8}$ or students spending time on social media or sleeping when in class. ${ }^{31}$ This was also acknowledged by the study participants, $90 \%$ of which acknowledged that they are more likely to feel sleepy during traditional lectures. With TBL, however, there is no time for passive behavior. At the start of the class, students participate in the readiness assurance process (RAP) where they are expected to complete a 10-20 multiple-choice question test, first individually to measure their level of preparedness for the class, and then again as a team. After a short discussion of the test and to clarify misunderstandings, the remainder of the class is spent on application exercises. In this study, both the individual and team tests contributed toward students' course grades. Although the application exercise did not contribute toward the course grade, similar questions formed part of the formal assessments in the course which contributed toward the course grade. It is clear why the participants agreed that TBL increased their class attendance and participation in class. We conclude that due to the valuable content of class activities, which they cannot study on their own or memorize, students were encouraged to come to class as they realized the benefit to their own learning.

One of the principles that differentiate TBL from other small group-based educational strategies is the importance of properly formed and managed teams. ${ }^{1}$ Teams should be as heterogeneous as possible to ensure that teams function as effectively as possible. Each team should have a mix of student characteristics, eg demographics like gender and ethnicity. ${ }^{1}$ In a study conducted in Oman, students were randomly sorted into teams consisting of members of the same gender because of the cultural sensitivities in this country regarding mixing of genders. ${ }^{32}$ When these students were asked whether they would prefer to be in a mixed gender TBL team, students strongly disagreed. The authors concluded that this behavior could be due to the fact that university is the first setting where both genders share a common learning environment. In South Africa, a country with 11 official languages, the population consists of diverse cultures. Pharmacists in South Africa will thus work with colleagues and other health care professionals representing different cultures and ethnicity, as enforced by legislation. ${ }^{26}$ Sweet explains the formation of fair teams which starts by identifying several characteristics which would make the course easier or more difficult for students. ${ }^{33}$ To ensure the above-mentioned diversity is represented in the teams during this study, one of the criteria used to form the teams was "all students who are not a South African citizen or whose mother-tongue is not Afrikaans." Unfortunately, as indicated in Table 1, due to the low number of male students and students from other ethnic groups other than white, not all teams were evenly diversified in terms of gender and ethnicity. Nevertheless, students indicated that they prefer to work in a multicultural and mixed gender team.

It was also rewarding to see that students were very positive (strongly agree) about working with their peers in the classroom. Students agreed that TBL is an effective teaching strategy to simulate the reality of the health profession where one is required to work in a team and motivated them to give their best in this course.

The older the students were, the more positively they experienced TBL. It could be that students older than 22 years who had been studying for longer or entered university later in life are more mature than the younger students. This enabled them to identify and accept the benefits of TBL for their future professional life earlier, which resulted in a better overall experience of TBL.

Students with a higher external motivation to prepare for class felt more positively about TBL. This is understandable as TBL relies on a scaffolding of individual accountability toward preparation for class. If students are not highly motivated, they will not have a favorable experience of TBL as they will not perceive it as enjoyable, valuable or worthwhile. This is also true for class attendance and participation. A student who attends class 


\section{American Journal of Pharmaceutical Education 2018; 82 (1) Article 6167.}

and participates as required in team activities will have a better experience of TBL than a student who does not attend class or does not participate. Since the majority of class time in TBL consists of working in teams, an enjoyable experience of working in teams will result in an enjoyable experience of TBL. Students' behavior and attitude toward class attendance and participation will influence their experience of working in teams since TBL enforces in-class team activities where they are required to attend class and participate in activities. It is clear that all facets of TBL are interrelated and build onto each other.

Female students initially had a more negative perception of TBL immediately after it was introduced but prior to their practicing it for the first time. Female students also relied more on external motivational factors for them to prepare for class (eg, knowing they would discuss their opinions during class) than the male students. This factor led female students to report that they enjoyed working in a team more.

Non-white students also initially had a more negative perception of TBL. Even though they usually prepared for all classes initially to a greater extent than white students, it is possible that they were concerned about the impact of change and whether their current preparation methods would still be sufficient in TBL. However, white students enjoyed working in a team more than students from other ethnic groups and it could be debated that this is due to being in the minority during teamwork.

\section{CONCLUSION}

This article measured pharmacy students' learning experience with TBL for the first time in a South African pharmacy school. We conclude that students had similar experiences of TBL as predicted by Michaelsen and Sweet in terms of class attendance and preparation. ${ }^{1}$ The positive outcomes of TBL in this study highlights the need that TBL should be included early on in the BPharm and other health professions curriculums in South Africa. TBL simulates the real-world experience of the health professions team and fosters accountability and collaboration between team members, which are essential competencies and experiences that students should be exposed to from the start of their training and not only in the last year.

\section{ACKNOWLEDGMENTS}

Funding for this research was received from the Scholarship of Teaching and Learning at North-West University, Potchefstroom, South Africa.

\section{REFERENCES}

1. Michaelsen LK, Sweet M. Fundamental principles and practices of team-based learning. In: Michaelsen LK, Parmelee DX, McMahon KK, Levine RE, eds. Team-Based Learning for Health Professions Education: A Guide to Using Small Groups for Improving Learning. Sterling, VA: Stylus Publishing; 2007:9-34.

2. Parmelee DX. Team-based learning in health professions education. In: Michaelsen LK, Parmelee DX, McMahon KK, Levine RE, eds. Team-Based Learning for Health Professions Education: A Guide to Using Small Groups for Improving Learning. Sterling, VA: Stylus Publishing; 2007:3-8.

3. Sibley J, Ostafichuk P. Introduction to team-based learning. In: Sibley J, Ostafichuk P. Getting Started With Team-Based Learning. Sterling, VA: Stylus Publishing; 2014:3-15.

4. Altintas L, Altintas O, Caglar Y. Modified use of team-based learning in an ophthalmology course for fifth-year medical students. Adv Physiol Educ. 2014;38(1):46-48.

5. Michaelsen LK. Getting started with team-based learning. In: Michaelsen LK, Knight AB, Fink LD, eds. Team-Based Learning: A Transformative Use of Small Groups in College Teaching. Sterling, VA: Stylus Publishing; 2004:27-50.

6. Michaelsen LK, Knight AB, Fink LD. Preface. In: Michaelsen LK, Knight AB, Fink LD, eds. Team-Based Learning: A

Transformative Use of Small Groups in College Teaching. Sterling, VA: Stylus; 2004:vii-xi.

7. Michaelsen LK, Sweet M. The essential elements of team-based learning. In: Michaelsen LK, Sweet M, Parmelee DX, eds. TeamBased Learning: Small-Group Learning's Next Big Step: New Directions for Teaching and Learning, Number 116. San Francisco, CA: Jossey-Bass; 2008:7-27.

8. Hawkins D. Rationale and method for developing team-based learning education. In: Hawkins D, ed. A Team-Based Learning Guide for Faculty in the Health Professions. Bloomington, IN: AuthorHouse; 2014:1-10.

9. Farland MZ, Barlow PB, Lancaster TL, Franks AS. Comparison of answer-until-correct and full-credit assessments in a team-based learning course. Am J Pharm Educ. 2015;79(2):Article 21.

10. Allen RE, Copeland J, Franks AS, et al. Team-based learning in US colleges and schools of pharmacy. Am J Pharm Educ. 2013;77(6): Article 115.

11. Frame TR, Cailor SM, Gryka RJ, Chen AM, Kiersma ME, Sheppard L. Student perceptions of team-based learning vs traditional lecture-based learning. Am J Pharm Educ. 2015;79(4):Article 51.

12. Zingone MM, Franks AS, Guirguis AB, George CM, HowardThompson A, Heidel RE. Comparing team-based and mixed activelearning methods in an ambulatory care elective course. Am J Pharm Educ. 2010;74(9):Article 160.

13. Berk RA. Top 10 Flashpoints in Student Ratings and the Evaluation of Teaching: What Faculty and Administrators Must Know to Protect Themselves in Employment Decisions. Sterling, VA: Stylus Publishing; 2013:66-72.

14. Delport CSL, Roestenburg WJH. Quantitative data-collection methods: questionnaires, checklists, structured observation and structured interview schedules. In: De Vos AS, Strydom H, Fouché CB, Delport CSL. Research at Grass Roots: For the Social Sciences and Human Service Professions. $4^{\text {th }}$ ed. Pretoria, South Africa: Van Schaik Publishers; 2011:171-205.

15. Wills GB. Cognitive Interviewing: A Tool for Improving Questionnaire Design. Thousand Oaks, CA: Sage Publications; 2004:35-54. 


\section{American Journal of Pharmaceutical Education 2018; 82 (1) Article 6167.}

16. South Africa, Department of Health. Ethics in Health Research: Principles, Processes and Structures. 2nd ed. Pretoria, South Africa: Department of Health; 2015:25.

17. SPSS Inc. 2016. IBM SPSS Statistics Version 23, Release 23.0.0, IBM Corp. http://www-01.ibm.com/software/analytics/spss/.

Accessed August 10, 2016.

18. Field A. Discovering Statistics Using SPSS. 4th ed. London, UK: Sage Publications; 2014:685-686.

19. Pietersen J, Maree K. Standardisation of a questionnaire. In:

Maree K, ed. First Steps in Research. Pretoria, South Africa: Van Schaik Publishers; 2007:215-224.

20. Cao Y. Comparison of two modules of foreign language classroom anxiety scale. Philippine ESL J. 2011;7:73-93.

21. Blunch NJ. Introduction to structural equation modeling using IBM SPSS statistics and Amos. London, UK: Sage Publications; 2008:113-116.

22. Steyn HS Jr. Practically significant relationship between two variables. SA J of Indus Psych. 2002;28(3):10-15.

23. Pallant J. T-tests. In: Pallant J. SPSS Survival Manual. Crows Nest, NSW, Australia: Allen \& Unwin; 2005:205-213.

24. Cohen J. A power primer. Psychol Bulletin. 1992;112(1):155159.

25. Statistics 2016, South African Pharmacy Council. Persons by gender. www.sapc.za.org/B_StatsPerByGender.asp. Accessed July 29, 2016.
26. Employment Equity Act, Act 55 of 1998, South Africa Department of Labour. http://www.labour.gov.za/DOL/downloads/ legislation/acts/employment-equity/eegazette2015.pdf. Accessed August 1, 2016.

27. Conway SE, Johnson JL, Ripley TL. Integration of team-based learning strategies into a cardiovascular module. Am J Pharm Educ. 2010;74(2):Article 35.

28. Lubeck P, Tschetter L, Mennenga H. Team-based learning: an innovative approach to teaching maternal-newborn nursing care. $J$ Nurs Educ. 2013;52(2):112-115.

29. Mennenga HA. Team-Based Learning: Engagement and Accountability with Psychometric Analysis of a New Instrument $[\mathrm{PhD}$ dissertation]. Las Vegas, NV: University of Nevada, 2010.

30. Letassy NA, Fugate SE, Medina MS, Stroup JS, Britton ML. Using team-based learning in an endocrine module taught across two campuses. Am J Pharm Educ. 2008;72(5):Article 103.

31. Grady SE. Team-based learning in pharamcotherapeutics. Am J Pharm Educ. 2011;75(7):Article 136.

32. Inuwa IM. Perceptions and attitudes of first-year medical students on a modified team-based learning (TBL) strategy in anatomy. Sultan Qaboos University Med J. 2012;12(3):336-343. 33. Sweet M. Appendix 2.A Forming fair groups quickly. In: Michaelsen LK, Parmelee DX, McMahon KK, Levine RE, eds. Team-Based Learning for Health Professions Education: A Guide to Using Small Groups for Improving Learning. Sterling, VA: Stylus Publishing; 2008:32-34. 